\title{
Possible Impact of a Tropical Cyclone on the Northward Migration of the Baiu Frontal Zone
}

\author{
Tsuyoshi Yamaura ${ }^{1}$, Yoshiyuki Kajikawa ${ }^{1}$, Hirofumi Tomita ${ }^{1,2}$, and Masaki Satoh ${ }^{2,3}$ \\ ${ }^{1}$ RIKEN Advanced Institute for Computational Science, Kobe, Japan \\ ${ }^{2}$ Research Institute for Global Change, Japan Agency for Marine-Earth Science and Technology, Yokohama, Japan \\ ${ }^{3}$ Atmosphere and Ocean Research Institute, The University of Tokyo, Kashiwa, Japan
}

\begin{abstract}
The impact of a tropical cyclone on the northward migration of the Baiu frontal zone (BFZ) is investigated in the case of the tropical cyclone MAWAR (2012) using a global cloud-system resolving model, called NICAM. From 4 to 6 June in 2012, the BFZ rapidly shifts northward with MAWAR. A simulation with the initial data of 29 May reproduces the northward migration of the BFZ and the tropical cyclone. Strong southerlies on the eastern side of the tropical cyclone transport moist and high-temperature air into the BFZ. This horizontal advection affects the northward migration of the BFZ. In contrast, the BFZ stagnates to the south of Japan in another simulation with the initial data of 30 May because the tropical cyclone track is diverted eastward. Thus, realistic reproducibility of a tropical cyclone is needed for better simulations and prediction of the BFZ migration.
\end{abstract}

(Citation: Yamaura, T., Y. Kajikawa, H. Tomita, and M. Satoh, 2013: Possible impact of a tropical cyclone on the northward migration of the Baiu frontal zone. SOLA, 9, 89-93, doi:10.2151/ sola.2013-020.)

\section{Introduction}

Baiu (in Japanese; Mei-yu in Chinese; Changma in Korean) is a typical rainfall event with a quasi-stationary front in the summertime over East Asia. Many researchers have investigated heavy rainfall events caused by the stationary Baiu front (e.g., Ninomiya 2001; Kato 2006) and the abrupt withdrawal of Baiu (e.g., Nakazawa 1992; Ueda et al. 1995). Recently, it is suggested that rainfall events near a front are strengthened by a tropical cyclone, discussed as the predecessor rain events (PRE; Cote 2007; Wang et al. 2009; Galarneau et al. 2010; Bosart et al. 2012). Tropical cyclones have the radius of gale force winds which is often greater than $500 \mathrm{~km}$, inducing horizontal advection processes in that region. Horizontal water vapor transport with a tropical cyclone leads to anomalous precipitation near the Baiu frontal zone (BFZ; Yamaura and Tomita 2012; Yoshida and Itoh 2012).

Because heavy rainfall events frequently occur near the BFZ during the Baiu season, detailed understanding of the physical mechanism of BFZ migration can contribute to disaster prevention and the prediction of Baiu precipitation. The latitudinal migration of the BFZ has been kinematically explained by horizontal advection processes with a strong wind. Chen et al. (2006) has noted that the horizontal advection of potential vorticity associated with the lower level jet (LLJ) contributes to the northward migration of the BFZ. A tropical cyclone may also affect the migration of the BFZ because it can provide strong wind and water vapor for the BFZ.

Here, we address the following questions: Does a tropical cyclone cause the northward migration of the BFZ, and if so, what is the mechanism of this migration? We examine a case of northward BFZ migration in early June 2012. The Baiu front clearly

Corresponding author: Tsuyoshi Yamaura, RIKEN Advanced Institute for Computational Science, 7-1-26, Minatojima-minami-machi, Chuo-ku, Kobe, Hyogo 650-0047, Japan. E-mail: tyamaura@riken.jp. (C2013, the Meteorological Society of Japan. appeared to the south of Japan during this period. The tropical cyclone MAWAR (2012) simultaneously approached the Baiu front from the south. This case is suitable for investigating the behavior of the BFZ with a tropical cyclone.

\section{Data and model}

As an observational evidence, we employed the Japanese 25year Reanalysis (JRA-25)/Japan Meteorological Agency (JMA) Climate Data Assimilation System (JCDAS) reanalysis (Onogi et al. 2007) and the Tropical Rainfall Measuring Mission (TRMM; Huffman et al. 2007). The former is a 6 -hourly, $1.25^{\circ}$ global grid dataset, and the latter is a 3 -hourly, $0.25^{\circ}$ grid dataset from $50^{\circ} \mathrm{S}$ to $50^{\circ} \mathrm{N}$.

We also used the Nonhydrostatic Icosahedral Atmospheric Model (NICAM) (Satoh et al. 2008) for simulations. This model has the advantage of reproducing both synoptic-scale phenomena and the life cycle of cumulus convection. This advantage is crucial for realistically reproducing the genesis of a tropical cyclone and convective precipitation. Therefore, the NICAM is useful for the research on meteorological phenomena in the tropics, such as the Asian monsoon (Oouchi et al. 2009), tropical cyclones (Emanuel et al. 2010), and the Madden-Julian Oscillation (Miura et al. 2007). To realistically reproduce the Baiu front and the tropical cyclone MAWAR, numerical experiments were configured with a horizontal resolution equivalent to about a $14 \mathrm{~km}$ mesh and 38 vertical levels, with the model top at about $35 \mathrm{~km}$. To produce the divergence of the tropical cyclone track in the NICAM simulations, this study employed two initial data at 00 UTC on 29 and 30 May 2012 before 18 UTC 1 June when MAWAR grew into a tropical storm. To initialize the simulations, we applied the Grid Point Value (GPV) of the JMA Global Spectral Model (GSM) data for atmospheric parameters, the National Centers for Environmental Prediction (NCEP) finalized data for the ocean, and the long-term spin up data of the NICAM simulations with low resolution (equivalent to about $224 \mathrm{~km}$ mesh) for the land. The sea surface temperature (SST) was nudged with the weekly Reynolds SST (Reynolds and Smith 1994). The relaxation time of SST was 7 days. We then analyzed the horizontally and vertically interpolated output data of the numerical experiments. The horizontal grid interval was $1.25^{\circ}$ globally, and the vertical levels were the standard 17 pressure levels. The time interval of the output data was 3-hourly for three-dimensional variables and hourly for two-dimensional variables.

\section{Results and discussion}

To display the impact of different tropical cyclone tracks on the BFZ, we first diagnose observations and the two NICAM simulations in early June 2012. Because the BFZ is recognized as a large horizontal gradient of the equivalent potential temperature (EPT; Tomita et al. 2011), we define the BFZ as the area in which horizontal gradient of the EPT is large. The location of the tropical cyclone MAWAR in the observations is derived from the JMA best track data. Detection of the tropical cyclone in the simulations is based on the criteria shown in Oouchi et al. (2006). In the observation (Figs. 1a, b, c), the BFZ approximately corresponds 
to the EPT contours from $330 \mathrm{~K}$ to $340 \mathrm{~K}$, which clearly appears from 18 UTC on 3 June to 18 UTC on 5 June. MAWAR moves northeastward from $\left(21^{\circ} \mathrm{N}, 126^{\circ} \mathrm{E}\right)$ to $\left(30^{\circ} \mathrm{N}, 138^{\circ} \mathrm{E}\right)$ during this period. At 18 UTC on 4 June, local maximum rainfall areas appear around $\left(30^{\circ} \mathrm{N}, 129^{\circ} \mathrm{E}\right)$ and in the western Japan $\left(33^{\circ} \mathrm{N}, 132^{\circ} \mathrm{E}\right)$ near the BFZ. These rainfall areas are observed in places $600 \mathrm{~km}$ and $1000 \mathrm{~km}$ away from the tropical cyclone center, respectively. A large amount of water vapor is transported north-northwestward through $130^{\circ} \mathrm{E}-140^{\circ} \mathrm{E}$, which suggests rainfall strengthening. These characteristics are similar to the PRE. Then, MAWAR come close to the BFZ, and the BFZ protrudes northward at 18 UTC on 5 June. The rainfall area of MAWAR can be hardly distinguished from the rainfall area over the western Japan. In the NICAM simulation with the initial data of 29 May (Figs. 1d, e, f; case 0529 hereafter), the BFZ and MAWAR are realistically reproduced until 18 UTC on 4 June. Although the PRE near the BFZ is insignificant, a large amount of water vapor is transported from the east of MAWAR into the BFZ. MAWAR moves slowly around Okinawa at 18 UTC on 5 June, which displays the delayed movement of MAWAR in case 0529 compared with the observation. As seen in Fig. 1c, the southward kink in the western part of the BFZ doesn't appear because westward transport of water vapor is large by the cyclonic circulation. In contrast, another NICAM simulation with the initial data of 30 May does not reproduce the northward migration of the BFZ (Figs. 1g, h, i; case 0530 hereafter). The BFZ stagnates around $26^{\circ} \mathrm{N}$ during this period. The track of MAWAR is off to the east side of the observations. Here, it is important that large-scale atmospheric circulations are almost the same between the two simulations. In the two simulations, the initial dates are close and the integrated time is shorter than the time scale of development of baroclinic waves (about 1 week). The horizontal wind and geopotential height fields at $500 \mathrm{hPa}$ before 3 June are similar between the two simulations (not shown). Under these atmospheric conditions, if tracks of MAWAR are still different in the two simulations, a comparison of the two simulations suggests the impact of different tracks of a tropical cyclone. As such, these results suggest that a tropical cyclone track is important for the BFZ migration.

We then evaluate the time evolution of BFZ migration in early June 2012 (Fig. 2). In the observation, the BFZ is zonally elongated along $30^{\circ} \mathrm{N}$ at $18 \mathrm{UTC}$ on 4 June. The area in which the horizontal gradient of the EPT is larger than $2 \times 10^{-5} \mathrm{~K} \mathrm{~m}^{-1}$ migrates northward until 6 June, after expanding to the south on 3 June. The northward BFZ migration coincides with the northward movement of a strong cyclonic circulation by MAWAR. The area-averaged precipitation in the BFZ near the Pacific coast of Japan $\left(30^{\circ} \mathrm{N}-35^{\circ} \mathrm{N}, 130^{\circ} \mathrm{E}-140^{\circ} \mathrm{E}\right)$ is strengthened together with MAWAR approaching to the BFZ. The precipitation peak is displayed at 15 UTC on 5 June. In case 0529 , the BFZ and tropical cyclone simultaneously shift northward from 3 June until 6 June. Because the tropical cyclone wanders slowly around the south of the BFZ, carrying water vapor into the BFZ continuously during this period, the peak of precipitation on the Pacific coast of Japan is delayed about 1 day. In case 0530 , the cyclonic circulation shifts northward until 12 UTC on 3 June and then weakens, indicating that the tropical cyclone is off to one side. Little precipitation occurs along the Pacific coast of Japan during this period.

To ascertain how MAWAR influences the northward migration of the BFZ, we then examine the local tendency of the EPT. Because the EPT decreases northward in the Northern Hemisphere, the local tendency of the EPT is positive in the BFZ when the BFZ shows northward migration. The local tendency of the EPT is positive to the south of the BFZ when the BFZ is strengthened. This indicates the importance of the location of the area where the
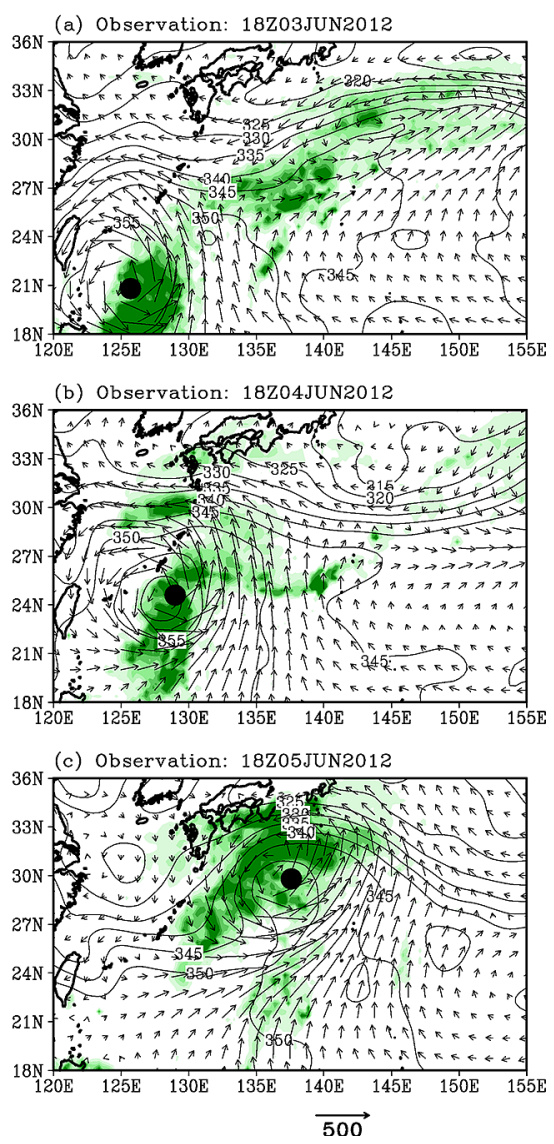
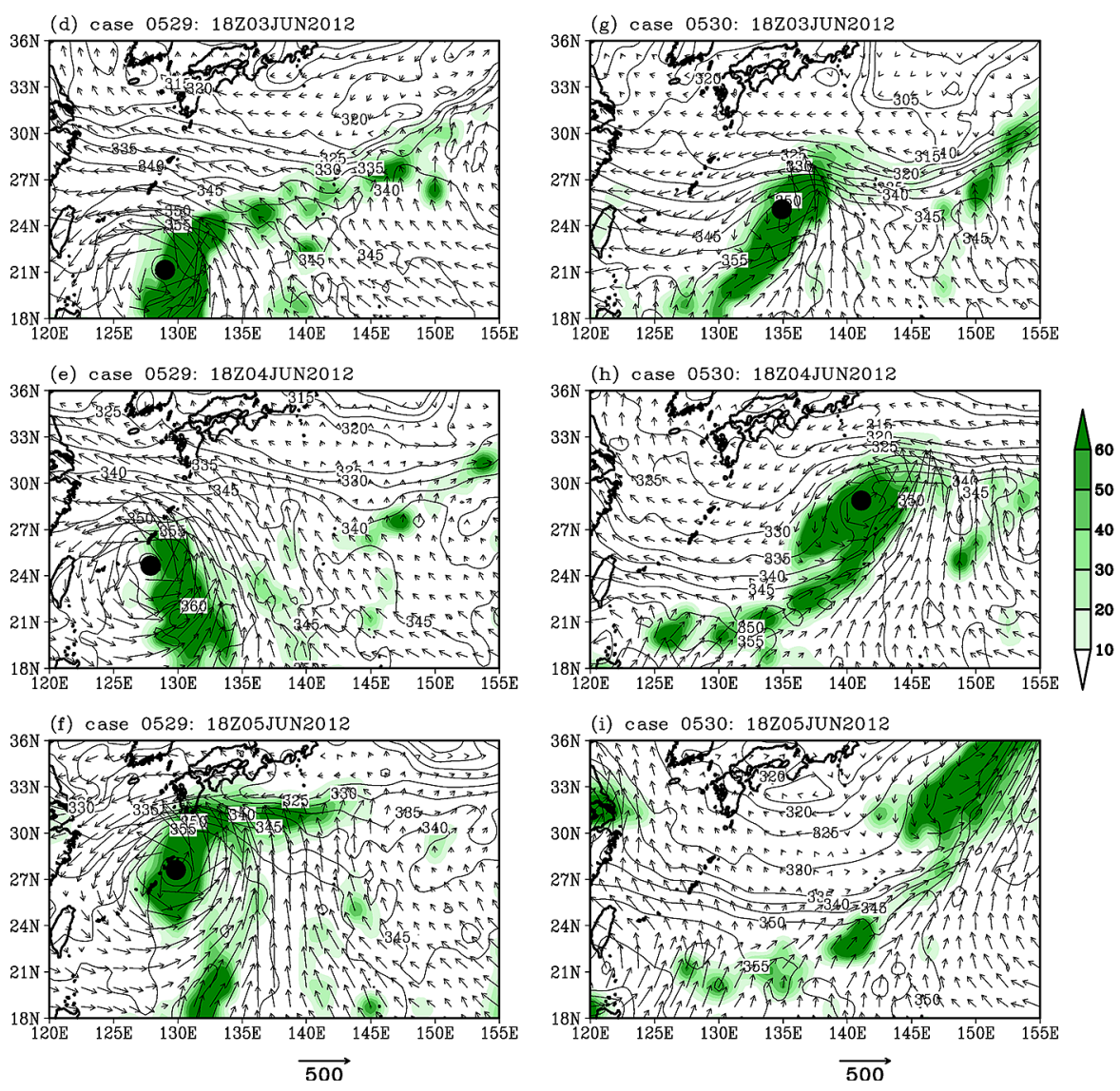

Fig. 1. (a-c) Accumulated rainfall over the past 24 hour (shade; $\mathrm{mm}$ ), the EPT (contours; $\mathrm{K}$ ), and water vapor flux (vector; $\mathrm{g} \mathrm{kg}^{-1} \mathrm{~m} \mathrm{~s}^{-1}$ ) at $925 \mathrm{hPa}$ at 18 UTC on 3, 4, and 5 June, respectively. The black circle indicates the location of the tropical cyclone MAWAR at the time. (d-f) Same as (a-c) except for case 0529. (g-i) Same as (a-c) except for case 0530 . 
local tendency of the EPT is positive. The equation for the local tendency of the EPT is defined as

$$
\frac{\partial \theta_{e}}{\partial t}=-\boldsymbol{V} \cdot \nabla \theta_{e}-\omega \frac{\partial \theta_{e}}{\partial p}+\boldsymbol{R}
$$

where $\theta_{e}$ is the EPT, $\boldsymbol{V}$ is the horizontal wind vector, $\nabla$ is the horizontal gradient operator, $\omega$ is the vertical pressure velocity, and $\boldsymbol{R}$ is a residual term, such as the effect of sub-grid scale motions or sensible/latent heat flux from the ocean. The first (second) term on the right side is the horizontal (vertical) advection term. The physical mechanism of the BFZ migration is established by analyzing the contribution of each term to the local tendency of the EPT. The equation is applied to the observational data and output of the model simulations (Fig. 3). Here, we define the $340 \mathrm{~K}$ contour of the EPT as the Baiu front because the contour corresponds to the southern edge of the BFZ (Fig. 2a). In the observations, the local tendency of the EPT is largely positive near the Baiu front between $130^{\circ} \mathrm{E}$ and $135^{\circ} \mathrm{E}$ at $18 \mathrm{UTC}$ on 4 June. Because the hor- izontal advection is comparable to the local tendency of the EPT, the contribution of horizontal advection dominates the tendency of the EPT. Northward water vapor fluxes are large over the longitudinal zone (Fig. 1b). These features are also found in case 0529 . In case 0530 , the Baiu front between $130^{\circ} \mathrm{E}$ and $140^{\circ} \mathrm{E}$ stagnates near $25^{\circ} \mathrm{N}$, where the local tendency of the EPT is small. A positive local tendency of the EPT appears to the east of $140^{\circ} \mathrm{E}$. The difference between cases 0529 and 0530 is related to the location of area where northward water vapor fluxes are large.

To reveal the contribution to the northward BFZ migration in detail, we display the contribution of horizontal advection, vertical advection, and residual term to the local tendency of the EPT in the latitude-height cross section around the BFZ (Fig. 4). At 18 UTC on 4 June, the Baiu front stands around $30^{\circ} \mathrm{N}$ in the observations. The local tendency and the horizontal advection of the EPT are significant from the surface to $500 \mathrm{hPa}$. The vertical advection has less contribution to the northward BFZ migration. Rather, the vertical advection moves the BFZ southward in the middle-upper troposphere. These horizontal and vertical advections coordinately
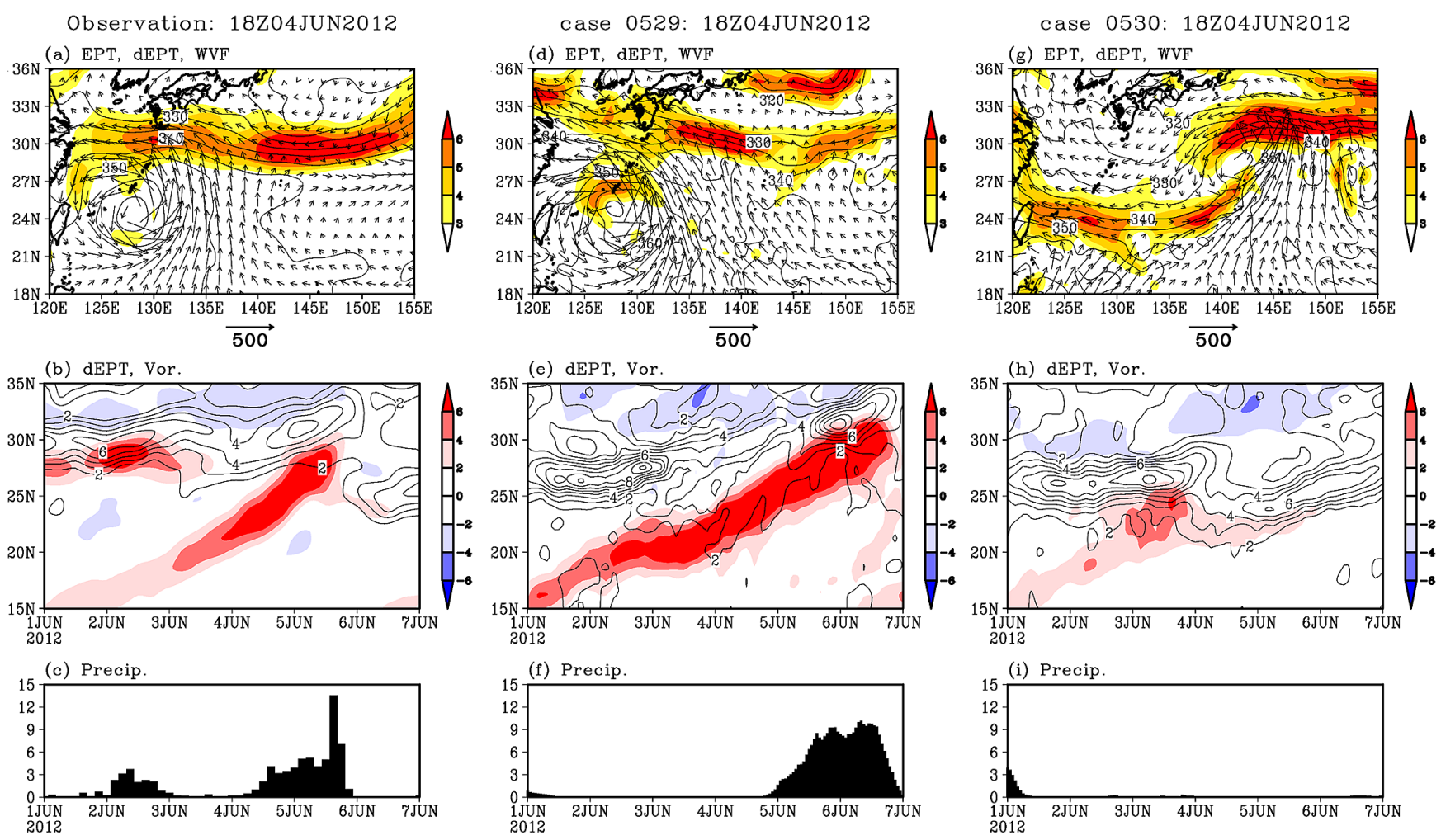

Fig. 2. (a) Horizontal map of the EPT (contour; K), its horizontal gradient (shade; $10^{-5} \mathrm{~K} \mathrm{~m}^{-1}$ ), and the water vapor flux (vector; $\mathrm{g} \mathrm{kg}^{-1} \mathrm{~m} \mathrm{~s}^{-1}$ ) at $925 \mathrm{hPa}$ and $18 \mathrm{UTC}$ on 4 June. (b) Latitude-time cross section of $130^{\circ} \mathrm{E}-140^{\circ} \mathrm{E}$ averaging the horizontal gradient of the EPT (contour; $10^{-5} \mathrm{~K} \mathrm{~m}^{-1}$ ) and $125^{\circ} \mathrm{E}-135^{\circ} \mathrm{E}$ averaging relative vorticity (shade; $10^{-5} \mathrm{~s}^{-1}$ ) at $925 \mathrm{hPa}$. The contour interval is $1 \times 10^{-5} \mathrm{~K} \mathrm{~m}^{-1}$ from $2 \times 10^{-5} \mathrm{~K} \mathrm{~m}^{-1}$. (c) Time variation of area-averaged precipitation (mm) near Japan $\left(30^{\circ} \mathrm{N}-35^{\circ} \mathrm{N}, 130^{\circ} \mathrm{E}-140^{\circ} \mathrm{E}\right)$. (d-f) Same as (a-c) except for case 0529. (g-i) Same as (a-c) except for case 0530.
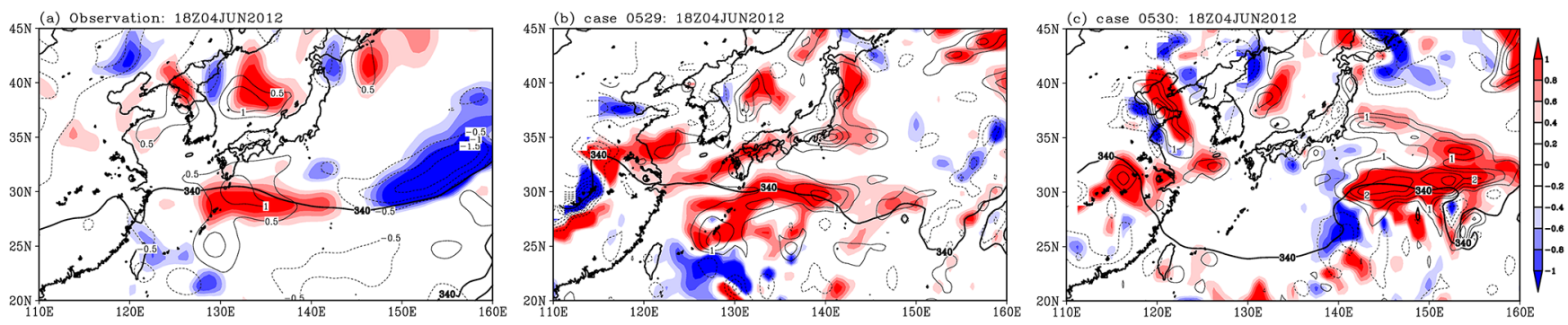

Fig. 3. (a) The $340 \mathrm{~K}$ contours of the EPT (thick contour; K), local tendency of the EPT (thin contour; $\mathrm{K} \mathrm{h}^{-1}$ ), and horizontal advection of the EPT (shade; $\mathrm{K} \mathrm{h}^{-1}$ ) at $925 \mathrm{hPa}$ and $18 \mathrm{UTC}$ on 4 June. The thin contour interval is $0.5 \mathrm{~K} \mathrm{~h}^{-1}$. The zero lines of the thin contour are omitted for clarity. (b) Same as (a) except for case 0529. (c) Same as (c) except for case 0530. 

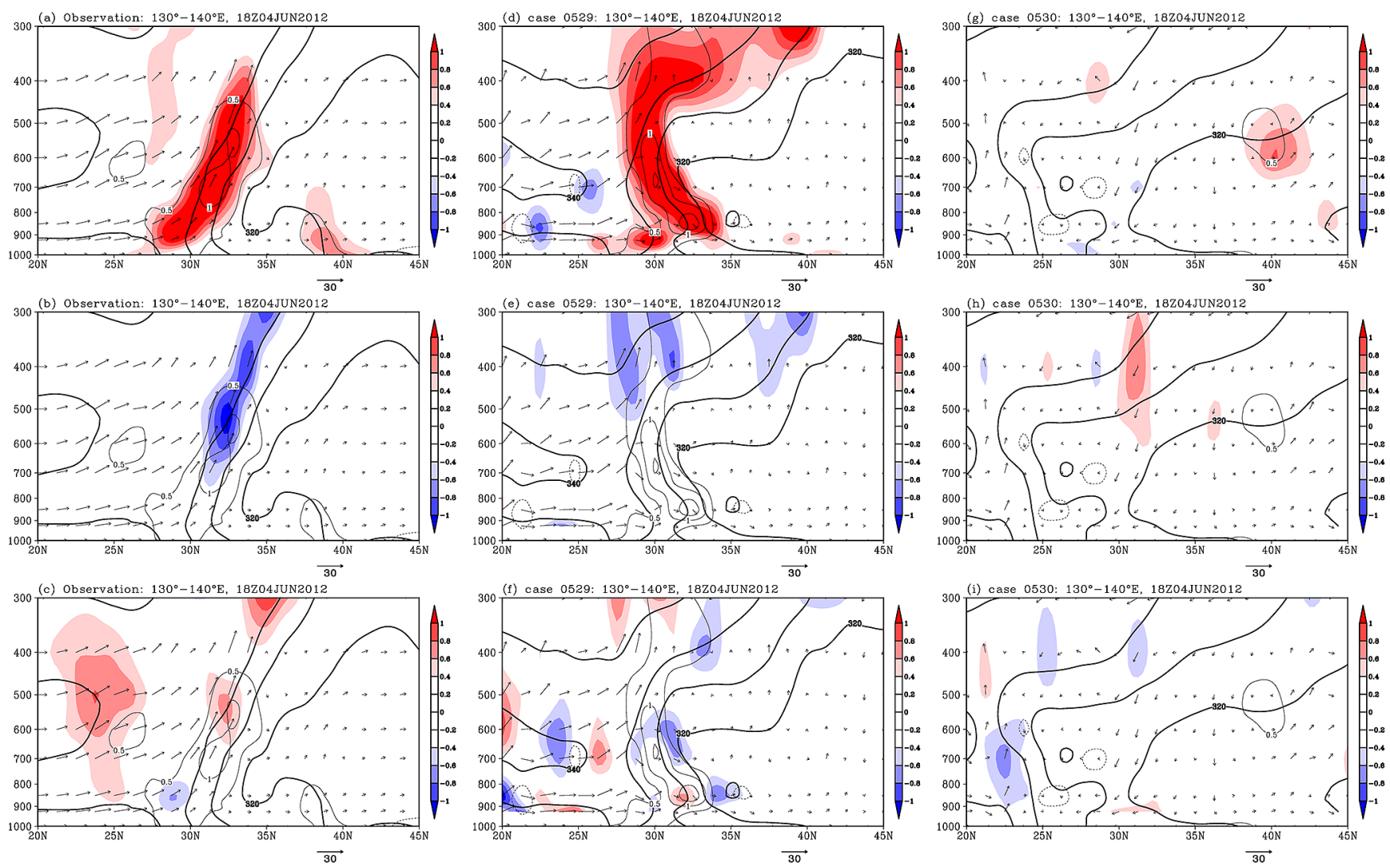

Fig. 4. (a-c) Latitude-height cross section of the EPT (thick contour; K), local tendency of the EPT (thin contour; $\mathrm{K} \mathrm{h}^{-1}$ ), meridional wind and vertical p-velocity (vector; $\mathrm{m} \mathrm{s}^{-1}$ and $\mathrm{hPa} \mathrm{h}^{-1}$ ) averaged between $130^{\circ} \mathrm{E}-140^{\circ} \mathrm{E}$ at $18 \mathrm{UTC}$ on 4 June. Shading in each panel indicates horizontal advection (top), vertical advection (middle), and residual (bottom) term of the EPT $\left(\mathrm{K} \mathrm{h}^{-1}\right)$. The thick (thin) contour interval is $10 \mathrm{~K}\left(0.5 \mathrm{~K} \mathrm{~h}^{-1}\right)$. Zero lines of thin contour are omitted for clarity. (d-f) Same as (a-c) except for case 0529. (g-i) Same as (a-c) except for case 0530.

change northward tilted EPT with the vertically uniform EPT, implying neutral stratification of the BFZ. The contribution of the residual is small in this case, although Ninomiya and Yamazaki (1979) pointed out the importance of vertical transport of the EPT by convection included the residual. The horizontal advection of the EPT dominates the local tendency of the EPT, with southerlies in the south of the BFZ, which suggests that the BFZ shifts northward consistently from the surface to $500 \mathrm{hPa}$. Case 0529 also shows that positive tendency of the EPT prevails from the surface to the upper troposphere in the BFZ. This is mainly caused by horizontal advection with the southerly in the south of the BFZ. In contrast with the observation, significant horizontal advection appears above $500 \mathrm{hPa}$. This is caused by zonal advection associated with westerly and the upper level trough that is slightly stronger than the observation (not shown). The vertical advection and the residual of the EPT are insignificant in the BFZ. The Baiu front in case 0530 appears around $25^{\circ} \mathrm{N}$. The local tendency of the EPT is insignificant around the BFZ, indicating stagnation of the Baiu front.

\section{Summary and discussions}

We investigated the northward migration of the BFZ as a tropical cyclone approached. Around the Pacific coast of Japan, the BFZ was northward-shifted during $48 \mathrm{~h}$ from 18 UTC on 3 June. The northward migration of the BFZ was reproduced in case 0529. Strong southerlies on the eastern side of the tropical cyclone carried moist and high-temperature air on the BFZ. This horizontal advection influenced the northward migration of the BFZ. The tropical cyclone MAWAR to the south of the BFZ induced the horizontal advection of EPT. In contrast, case 0530 failed to reproduce the northward migration of the BFZ. Because the track of MAWAR was averted eastward, moist and high-temperature air was transported far from Japan, and then the BFZ stagnated to the south of Japan. The two simulations successfully demonstrated that the BFZ stagnated to the south of Japan when the track of MAWAR was displaced to the side.

For the large track error in case 0530, the NICAM's spin-up time for convection is one possible reason. MAWAR became a tropical depression and a tropical storm in an active convection area over the Philippine Sea at 18 UTC 31 May (42 hours after the initial time) and 18 UTC 1 June (66 hours after the initial time), respectively. It might be too short for the NICAM to produce this active convection area in case 0530 simulation due to its model spin-up issue. Thus the genesis and the subsequent track predictions might have relatively large errors. The accurate prediction of tropical cyclogenesis events is still a challenging issue.

This work demonstrated one of the mechanisms of the BFZ migration. The BFZ migration is also caused by some other processes, such as convective activity in the Baiu front (Ninomiya and Yamazaki 1979) and horizontal advection by the LLJ (Chen et al. 2006). The dominance of each BFZ migration process is a challenging issue. Further study is necessary with a statistical analysis.

\section{Acknowledgments}

The authors acknowledge Dr. Yoshiaki Miyamoto for discussion on tropical cyclone activity and thank two anonymous reviewers for useful and constructive comments. Part of this work has been funded by MEXT Strategic Programs for Innovative Research (SPIRE). Part of the results is obtained by using the $\mathrm{K}$ computer at the RIKEN Advanced Institute for Computational Science (Proposal number hp120313). 


\section{References}

Bosart, L. F., J. M. Cordeira, T. J. Galarneau, Jr., B. J. Moore, and H. M. Archambault, 2012: An analysis of multiple predecessor rain events ahead of tropical cyclones Ike and Lowell: 10-15 September 2008. Mon. Wea. Rev., 140, 1081-1107.

Chen, G. T.-J., C.-C. Wang, and L.-F. Lin, 2006: A diagnostic study of a retreating Mei-yu front and the accompanying low-level jet formation and intensification. Mon. Wea. Rev., 134, 874-896.

Cote, M. R., 2007: Predecessor rain events in advance of tropical cyclones. M.S. thesis, Department of Atmospheric and Environmental Sciences, University at Albany, State University of New York, $198 \mathrm{pp}$.

Emanuel, K., K. Oouchi, M. Satoh, H. Tomita, and Y. Yamada, 2010: Comparison of explicitly simulated and downscaled tropical cyclone activity in a high-resolution global climate model. J. Adv. Model. Earth Syst., 2, Art. \#9, 9 pp., doi: 10.3894/JAMES.2010.2.9.

Galarneau, T. J. Jr., L. F. Bosart, and R. S. Schumacher, 2010: Predecessor rain events ahead of tropical cyclones. Mon. Weat. Rev., 138, 3272-3297.

Huffman, G. J., and co-authors, 2007: The TRMM Multisatellite Precipitation Analysis (TMPA): Quasi-global, multiyear, combined-sensor precipitation estimates at fine scales. $J$. Hydrometeor., 8, 38-55.

Kato, T., 2006: Structure of the band-shaped precipitation system inducing the heavy rainfall observed over northern Kyushu, Japan on 29 June 1999. J. Meteor. Soc. Japan, 84, 129-153.

Miura, H., M. Satoh, T. Nasuno, A. T. Noda, and K. Oouchi, 2007: A Madden-Julian Oscillation event realistically simulated using a global cloud-resolving model. Science, 318, 17631765 .

Nakazawa, T., 1992: Seasonal phase lock of intraseasonal variation during the Asian summer monsoon. J. Meteor. Soc. Japan, 70, 597-611.

Ninomiya, K., 2001: Large $\lambda$-shaped cloud zone formed around July 6, 1991 with pole-ward moisture transport from intense rainfall area in Meiyu-Baiu front. J. Meteor. Soc. Japan, 79, 805-813.

Ninomiya, K., and K. Yamazaki, 1979: Heavy rainfalls associated with frontal depression in Asian subtropical humid region. $J$.
Meteor. Soc. Japan, 57, 399-413.

Onogi, K., and co-authors, 2007: The JRA-25 Reanalysis. J. Meteor. Soc. Japan, 85, 369-432.

Oouchi, K., J. Yoshimura, H. Yoshimura, R. Mizuta, S. Kusunoki, and A. Noda, 2006: Tropical cyclone climatology in a global-warming climate as simulated in a $20 \mathrm{~km}$-mesh global atmospheric model: Frequency and wind intensity analyses. J. Meteor. Soc. Japan, 84, 259-276.

Oouchi, K., A. T. Noda, M. Satoh, B. Wang, S.-P. Xie, H. G. Takahashi, and T. Yasunari, 2009: Asian summer monsoon simulated by a global cloud-system-resolving model: Diurnal to intra-seasonal variability. Geophys. Res. Lett., 36, L11815, doi:10.1029/2009GL038271.

Reynolds, R. W., and T. M. Smith, 1994: Improved global sea surface temperature analyses using optimum interpolation. $J$. Climate, 7, 929-948.

Satoh, M., T. Matsuno, H. Tomita, H. Miura, T. Nasuno, and S. Iga, 2008: Nonhydrostatic Icosahedral Atmospheric Model (NICAM) for global cloud resolving simulations. Journal of Computational Physics, the special issue on Predicting Weather, Climate and Extreme events, 227, 3486-3514, doi:10.1016/j.jcp.2007.02.006.

Tomita, T., T. Yamaura, and T. Hashimoto, 2011: Interannual variability of the Baiu season near Japan evaluated from the equivalent potential temperature. J. Meteor. Soc. Japan, 89, 517-537.

Ueda, H., T. Yasunari, and R. Kawamura, 1995: Abrupt seasonal change of large-scale convective activity over the western Pacific in the northern summer. J. Meteor. Soc. Japan, 73, 795-809.

Wang, Y., Y. Wang, and H. Fudeyasu, 2009: The role of typhoon Songda (2004) in producing distantly located heavy rainfall in Japan. Mon. Wea. Rev., 137, 3699-3716.

Yamaura, T., and T. Tomita, 2012: Covariability between the Baiu precipitation and tropical cyclone activity through largescale atmospheric circulations. J. Meteor. Soc. Japan, 90, 449-465.

Yoshida, K., and H. Itoh, 2012: Indirect effects of tropical cyclones on heavy rainfall events in Kyushu, Japan, during the Baiu season. J. Meteor. Soc. Japan, 90, 377-401.

Manuscript received 7 March 2013, accepted 28 May 2013

SOLA: http://www.jstage.jst.go.jp/browse/sola 